\title{
AGENDAMENTO NA EXPEDIÇÃO DE PRODUTOS ACABADOS DA VOTORANTIM SIDERURGIA*
}

\author{
Daniel Valente Guimarães ${ }^{1}$ \\ João Batista de Souza Ferraz ${ }^{2}$ \\ Jorge Roberto Silva Dias ${ }^{3}$ \\ Ricardo do Nascimento Bueno ${ }^{4}$
}

\section{Resumo}

Este trabalho tem como objetivo apresentar os resultados alcançados através do planejamento, por meio do agendamento com hora marcada, no processo de expedição de produtos acabados, que estão permitindo a Votorantim Siderurgia atratividade na contratação de veículos, redução de custos e confiabilidade no processo.

Palavras-chave: Planejamento; Redução de custos; Confiabilidade, Agendamento.

\section{FINISHED PRODUCTS SCHEDULING IN SHIPPING PROCESS AT VOTORANTIM SIDERURGIA}

\section{Abstract}

This paper aims to present the results achieved through the planning, by schedule appointment in the finished products shipping process, who are allowing Votorantim Long Steel achievements attractiveness in hiring vehicles, cost reduction and process reliability.

Keywords: Planning; Cost reduction; Attractiveness; Scheduling. 


\section{1) INTRODUÇÃO}

O mercado siderúrgico de 2009 até os dias de hoje apresenta um cenário onde as margens de lucros estão cada vez mais reduzidas, pois o balanço entre o preço do produto e o custo com insumos e serviços estão cada vez menores.

Se analisarmos o processo de siderurgia, o controle dos custos internos, da negociação de frete e compra de insumos são de suma importância para que a organização continue competitiva no mercado, para que a mesma continue rentável para os acionistas, mesmo com o preço abaixo do esperado, que vem sendo determinado pela demanda do mercado.

Neste cenário faz-se necessário a fidelização do cliente, buscando entender suas necessidades para atendê-las ou superá-las. Hoje reconquistar um cliente está cada vez mais difícil e caro do que mantê-lo ou conquistar um novo cliente ${ }^{1}$.

$\mathrm{Na}$ siderurgia, a qualidade dos produtos está similar entre as organizações, visto que, os produtos são regulamentados por normas técnicas, com pouca diferença que o cliente realmente possa definir como uma vantagem competitiva, as organizações que hoje não conseguem acompanhar o nível dos produtos da concorrência, naturalmente são eliminadas do mercado.

Certamente que, em um mercado de produtos classificados como commodities, a principal diferenciação das empresas está nos serviços oferecidos. Serviços esses que, até pouco tempo, faziam parte de um pacote que era entendido como "Suporte ou Facilitador" de venda e atualmente, é entendido pelas empresas como "Diferenciador" na conquista de uma venda. Um dos serviços mais importantes deste pacote é, sem sombra de dúvidas, o de transporte do produto até a entrega final no cliente.

Tendo em vista o cenário da relevância do serviço de transportes e dos altos custos evolvidos, este trabalho se propõe a demonstrar como o planejamento passou a ser de suma importância para o processo logístico que envolve a Votorantim Siderurgia e os transportadores contratados por ela.

\section{2) METODOLOGIA}

\subsection{Estudo e Análise do Cenário do Planejamento Logístico}

Antes visto apenas como um simples prestador de serviço, a logística hoje atua com foco no cliente permitindo avançar, além das formas tradicionais de movimentação de materiais, em direção a uma ferramenta poderosa na agregação de valor aos serviços oferecidos e, também, conquistando vantagens competitivas perante a concorrência². Ao longo dos anos, a equipe de Supply Chain da Votorantim Siderurgia vem trabalhando para equalizar a relação entre disponibilidade da carteira de pedidos versus capacidade de embarques e disponibilidade de veículos para atender tamanha concentração de demanda, principalmente na última semana dos meses, nas vendas de produtos siderúrgicos.

Não obstante, ao longo de 2013, neste mesmo renomado congresso, essa equipe apresentou, inclusive, um trabalho dentro dessa ótica, ao qual relacionava gestão de estoques e capacidade de expedição com os resultados no nível de serviço ao cliente.

\footnotetext{
1 DRUCKER, Peter - Administração e Marketing - Análise, Planejamento e Controle. Ed. Atlas, 1985.

2 BALLOU, Ronald H. Gerenciamento da cadeia de suprimentos: planejamento, organização e logística empresarial. $4^{a}$ ed. Porto Alegre: Bookmann, 2001.
} 
$\mathrm{Na}$ época, o trabalho compreendia melhorias no planejamento e disponibilidade de produtos, bem como evolução na capacidade de expedição.

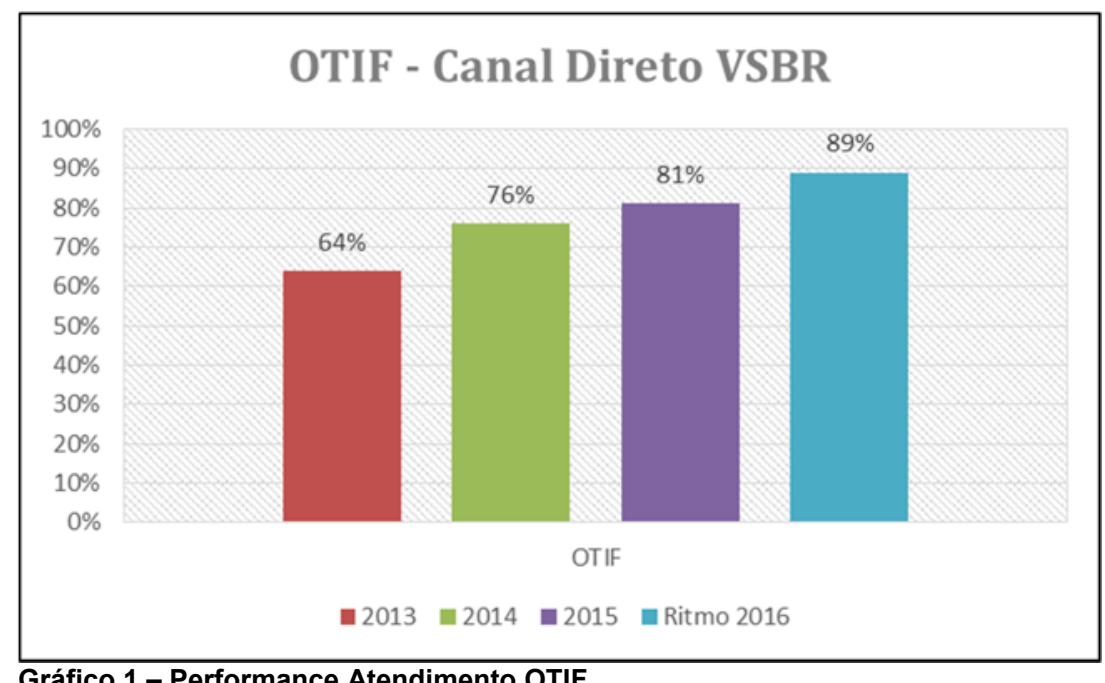

Após esse trabalho, com o qual alcançamos evolução significativa nos indicadores de atendimento ao cliente (gráfico 1 - OTIF), onde percebemos a evolução significativa no indicador de atendimento ao cliente, OTIF (On Time In Full) o próximo passo seguiu para melhoria nas disponibilidades de recursos de transportes (caminhão).

Com a evolução na disponibilidade de produtos e na geração do planejamento de embarque, com geração do documento de transportes, que é o documento oficial que a Votorantim Siderurgia formaliza a disponibilidade da carga para o transportador, começamos a encontrar outra dificuldade: a concentração na chegada dos veículos para o carregamento, em sua maior parte, de maneira desordenada, totalmente fora do alinhamento com nossa capacidade de expedição horária.

No contrato que a VS firmou com seus transportadores, tem-se o compromisso de 93\% (meta $300^{3}$ ) e 95\% (meta 5004) da marcação das cargas em D+1 (um dia após a geração da carga). Conforme mostra o gráfico 2 abaixo, os resultados no trabalho de disponibilidade de caminhões, dentro de um melhor planejamento e maior previsibilidade, vem sendo alcançado.

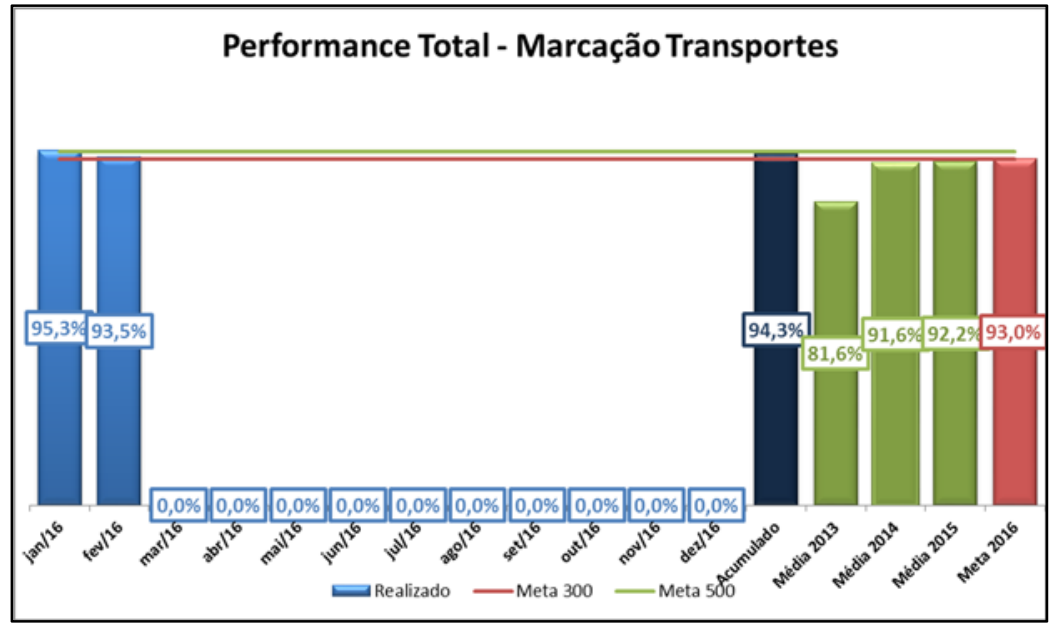

Gráfico 2 - Controle de Performance na marcação veículos em D+1

\footnotetext{
${ }^{3}$ Sistema de Metas da Votorantim - o 300 significa alcance do orçamento para o período.

${ }^{4}$ Sistema de Metas da Votorantim - o 500 significa uma superação máxima ao orçamento.
} 
O sucesso na contratação de veículos, por outro lado, trouxe complicadores aos quais a VS não estava preparada, uma vez que, no contrato com os transportadores, não se mencionava como deveriam ser disponibilizados os veículos, dentro de uma faixa de horários, conforme a capacidade das docas de carregamento. Não existia no contrato, porque, na prática, também não existia esse modelo de trabalho na operação.

Assim, tendo como parâmetro uma capacidade de carregamento limitada aos recursos disponíveis, por hora, as horas ociosas por falta de marcação dos veículos, não tinham suas capacidades aumentadas nos momentos de marcação/disponibilidade de caminhões acima da capacidade de carregamento. Essa fórmula (falta de veículos em alguns horários e excesso de veículos disponíveis em outros horários) começou a impactar muito tanto no nível de satisfação dos transportadores e motoristas que eram contratados para retirar carga nas usinas da Votorantim Siderurgia, quanto nos gastos relacionados a conta frete, mais precisamente, na parte de complementos, da qual faz parte a linha Diárias / Estadias. Dentro da ótica das estadias, vale ressaltar que a mesma, é regulamentada por lei (Artigo 15, parágrafo $5^{\circ}$ da Lei 13.103 de 02 de março de 2015 , sendo precedida pela Lei 11.442 de 05 de janeiro de 1997, no seu Artigo 11 parágrafos $5^{\circ}$ e $6^{\circ}$ ), sendo estabelecido uma penalização, em forma de multa, aos embaçadores que não realizarem operação de carga e/ou descarga em um período máximo de seis horas, a partir do momento da chegada do veículo em suas dependências. Todavia. No contexto da Lei 11.442, o texto permitia, desde que constasse em contrato, que o tempo de operação fosse maior que o previsto na lei. Com a Lei 13.103, a possibilidade de se manter um veículo a disposição do embarcador sem a devida penalização foi extinta, passando a ser um item de penalização obrigatória.

Desta forma, mesmo tendo em vista de que, menos de $50 \%$ das estadias geradas eram cobradas por parte dos transportadores, os custos envolvidos nesse processo não paravam de aumentar.

Ainda que tais custos não eram todos transformados em despesas efetivas, existia a preocupação de que, mesmo em posse de uma carta de isenção de ônus, que anualmente é emitido pelos transportadores para a Votorantim Siderurgia, a parte da "dívida" relacionada às estadias, pudesse ser cobrada, principalmente por motoristas autônomos $^{5}$, a qualquer tempo, dentro do prazo legal previsto no código civil, que considera que uma dívida prescreve após dez anos, quando não previsto outro prazo, em lei.

A geração de estadias é consequência dos elevados tempos que são gerados nas operações de carregamento. Um dos principais motivos destes tempos está relacionado diretamente à concentração de marcação dos veículos de maneira indiscriminada, sem a devida consideração às capacidades de carregamento das docas existentes.

O quadro abaixo demonstra o TPV (Tempo de Permanência dos Veículos), na unidade de Resende, no processo de carregamento de produtos acabados, nos anos de 2014 e no período de 2015 , anterior ao início do trabalho de agendamento.

\footnotetext{
${ }^{5}$ A VS não contrata diretamente motoristas autônomos, ficando a carga das transportadoras as quais mantem contrato, essa subcontratação. Em média, 50\% dos veículos que atendem as unidades se enquadram nesta categoria.
} 


\section{$35^{\circ}$ Logística}

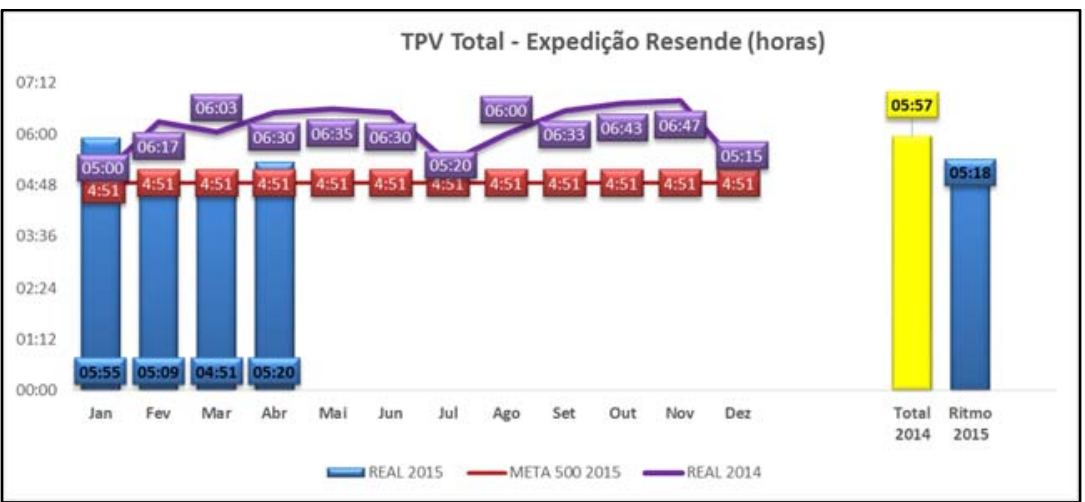

Quadro 3 - Tempo de permanência de Veículos (2014 a 2015), no processo de Expedição da unidade de Resende, Rio de Janeiro.

O quadro abaixo mostra a evolução na geração das estadias, apenas no processo de carregamento de produtos acabados, na usina de Resende, no Estado do Rio de Janeiro.

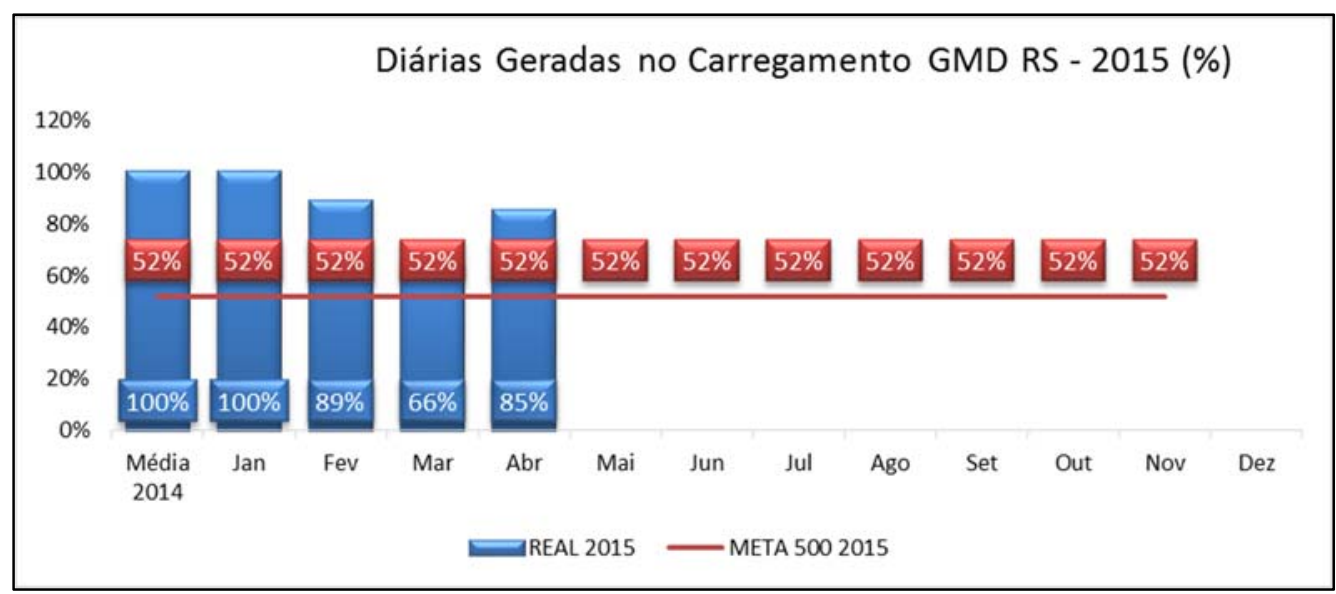

Quadro 4 - Geração mensal de estadias, em 2015, no processo de Expedição da unidade de Resende, Rio de Janeiro (posição em Maio/2015).

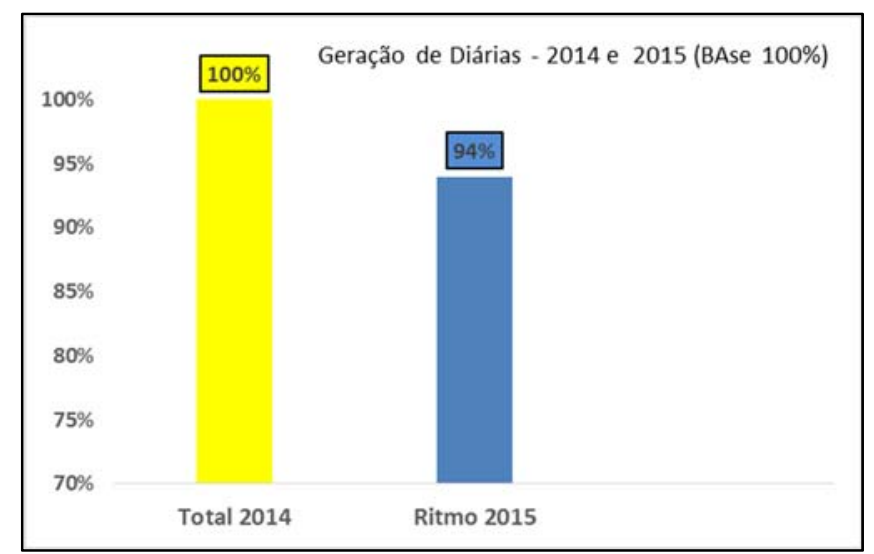

Quadro 5 - Geração anual de estadias no processo de Expedição da unidade de Resende, Rio de Janeiro (posição em maio/2015).

Conforme demonstrado no quadro 5 , o tempo médio de permanecia de veículos era de quase seis horas em 2014, o que nos apresentava, na mesma época, uma geração de estadias acima de um milhão de reais, somente na usina de Resende, onde o processo de carregamento tem um nível de complexidade inferior ao da usina de Barra Mansa. 


\subsection{Da Teoria para a Prática}

Partindo deste cenário e, com a certeza de que alguma coisa muito urgente deveria ser feita, a fim de reduzir os tempos de permanência dos veículos, garantindo assim, interrupção da crescente geração de diárias e, consequentemente, enorme perda de produtividade no fluxo logístico, iniciamos trabalho para o desenho de um modelo de agendamento, juntamente com os transportadores que prestam serviço nas unidades do Rio de Janeiro.

Inicialmente, havia uma enorme resistência, por parte dos transportadores e, até mesmo, por parte da equipe VS, com relação a confiabilidade de se trabalhar, dentro de um processo siderúrgico, com operações dessa natureza.

Após diversas reuniões e discussões sobre o modelo e o alcance desse processo, decidimos iniciar, de maneira parcial, em poucas docas (das onze docas de carregamento, iniciamos, no primeiro mês, em apenas três).

O primeiro passo foi desenhar, de maneira mais clara, a capacidade horária de carregamento (quadro 6), de cada doca, e desenhar esses dados em uma planilha de excel, onde foi montado a base para nosso agendamento. De posse das capacidades horárias, de cada doca de carregamento, definimos os desenhos das disponibilidades e como seria o modelo de registros, informe de contingencias e o processo de agendamento em si.

\begin{tabular}{|c|c|c|c|c|c|c|c|}
\hline & & AGENDAMENTO & & & & & \\
\hline & & Fio Máquina MI & & & & & \\
\hline & & HORAS & & & & & \\
\hline Hora & Transporte & Transportadora & DATA / HORA & & & & \\
\hline $17: 00: 00$ & 17986986 & steling & 21/09-07:09 & & & & \\
\hline 17:00:00 & 17986985 & steling & 21/09 - 07:10 & & & & \\
\hline $17: 00: 00$ & & & & & & & \\
\hline 18:00:00 & 17986987 & steling & $21 / 09-07: 10$ & & & GENDAMENTO & \\
\hline 18:00:00 & 17986852 & steling & 20/09 - 18:19 & & & CA50 Barra & \\
\hline 18:00:00 & & & & & & HORAS & \\
\hline & & & & Hora & Transporte & Transportadora & DATA / HORA \\
\hline 19:00:00 & & & & 18:00:00 & 31674813 & TRANSPEDROSA & 21/09/2015 09:30 \\
\hline & BLO & QUEADO & & 18:00:00 & 31673541 & s\&a & $21 / 09-16: 59$ \\
\hline & & & & 19:00:00 & 17986769 & trevo & 21/09/2015 09:50 \\
\hline 20:00:00 & & & & 19:00:00 & 31675221 & TNL & $21 / 09-18: 05$ \\
\hline & & & & 20:00:00 & 17985269 & $S \& A$ & 21/09/2015 10:35 \\
\hline 21:00:00 & 17986410 & transfuturo & $21 / 09 / 201508: 20$ & 20:00:00 & 31675223 & TNL & 21/09 - 18:07 \\
\hline 21:00:00 & 17986410 & transfuturo & $21 / 09 / 201508: 20$ & 21:00:00 & 17986854 & $S \& A$ & $21 / 09 / 2015$ 10:35 \\
\hline 21:00:00 & & & & 21:00:00 & & & \\
\hline 22:00:00 & 17986416 & transfuturo & $21 / 09 / 201508: 20$ & $22: 00: 00$ & 31674812 & $\mathrm{tnl}$ & 21/09/2015 11:00 \\
\hline 22:00:00 & 17986416 & transfuturo & $21 / 09 / 201508: 20$ & 22:00:00 & 18004608 & SUPRICEL & 29/09 - 11:58 \\
\hline 22:00:00 & & & & 23:00:00 & & & \\
\hline 23:00:00 & 17986693 & transfuturo & $21 / 09 / 2015$ 08:20 & $23: 00: 00$ & & & \\
\hline
\end{tabular}

Assim, seguindo o fluxo demonstrado no quadro abaixo, iniciamos processo de agendamento. 


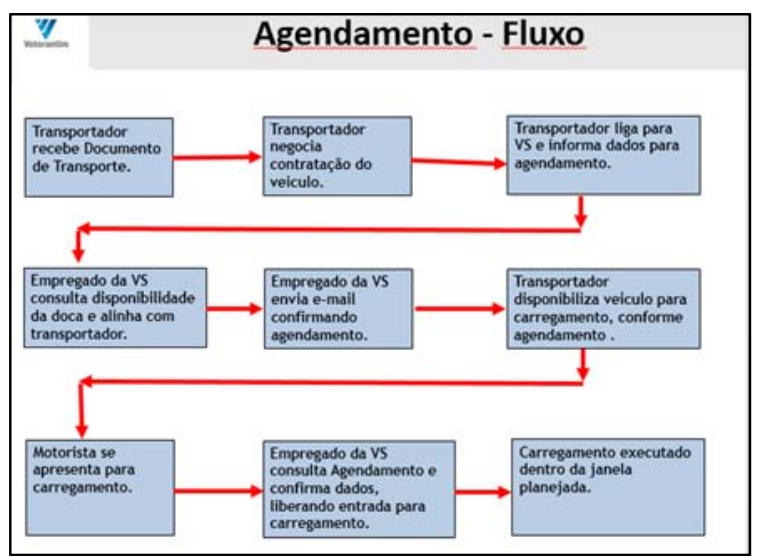

Quadro 7 - Fluxo detalhado de funcionamento do agendamento (Operação VS + Transportadoras)

Ao término da ligação para o agendamento, o empregado da VS envia um e-mail (modelo abaixo), formalizando o aceite do mesmo.

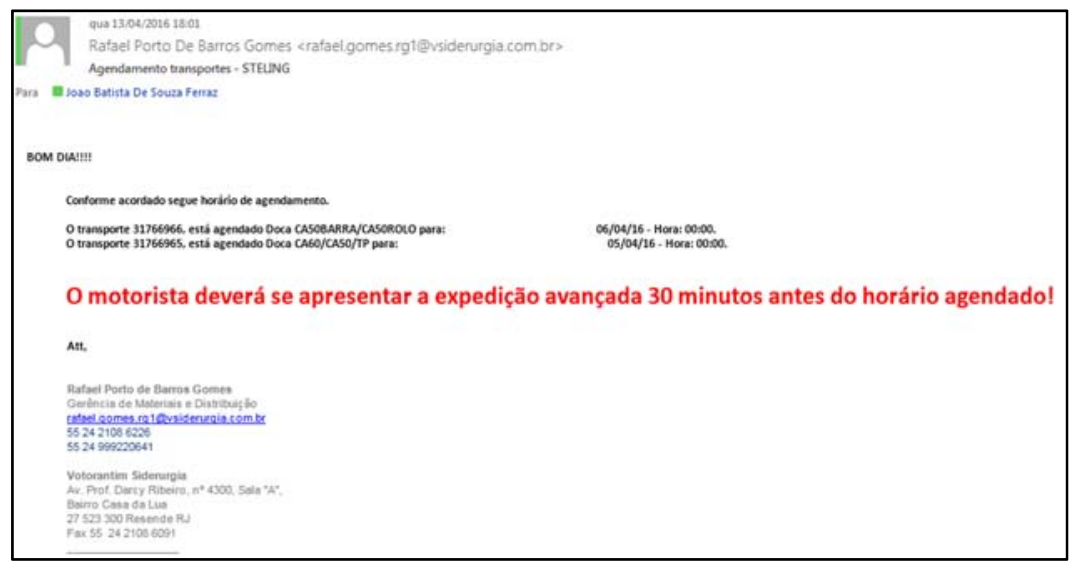

Quadro 8 - Cópia do e-mail padrão de confirmação do agendamento

Esse horário passa a ser o compromisso da Transportadora com a Votorantim Siderurgia e vice e versa.

Assim, de maneira simples mas eficaz, teve início o processo de agendamento para carregamento com hora marcada, nas unidades da Votorantim Siderurgia, no Sul Fluminense.

Entendemos como eficaz, pois ainda dependemos de se ter um empregado disponível para atender as ligações (se considerarmos que, somado as duas unidades do Sul Fluminense, o volume de veículos envolvidos no processo de expedição chega, em média, quase quatro mil veículos por mês).

Todavia, entendendo da importância do trabalho e conhecendo os ganhos que o mesmo gerou, tanto para o processo de carregamento, quanto para os transportadores e motoristas, a liderança da Votorantim Siderurgia disponibilizou recursos para que fosse estruturado um processo de automação do agendamento, onde teríamos capacidade de absorver todas as outras operações das unidades, a saber:

- Descarga de Metálicos;

- Recebimento de Insumos;

- Carregamento de Resíduos

- Descarga nas unidades comerciais da Votorantim Siderurgia (Filiais) 
Diante dessa possibilidade, iniciamos o trabalho para realização do agendamento via web access, através de uma plataforma de internet, gerando interface com nosso ERP (SAP/3), onde não mais será necessária realização de ligações para o agendamento, gerando maior produtividade ao modelo e aumentando capacidade do mesmo.

Abaixo, está demonstrado o cronograma para implantação do modelo de agendamento via internet, que se encontra em fase de implementação.

\begin{tabular}{|c|c|c|c|c|c|}
\hline$\overline{10}$ & 0 & Nome da tarefs & Dursson & start & Finleh \\
\hline 0 & & Projeto Agend. Velculos - V2 & 92 days & Mon 28103/16 & Thu $0408 / 16$ \\
\hline 1 & & Fase 1 - Iniclaça & 3 days & Mon 28/03/16 & W Wed $30 / 03 / 16$ \\
\hline 11 & & Fase 2 - Planejamento & 19 days & Mon 04/04/16 & Fri 29/04/16 \\
\hline 12 & 亚 & Visita a Unidade & 2 days & Mon $04 / 04 / 16$ & Tue 05/04/16 \\
\hline 13 & & Levantamento Requisitos & 3 days & Wed 06/04/16 & Fri 08/04/16 \\
\hline 14 & 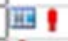 & Documentar Requisitos (BPP) & 5 days & Mon $11 / 04 / 16$ & Fri $15 / 04 / 16$ \\
\hline 15 & $\mathbf{1}$ & Prototipagem e Design & 5 days & Mon $11 / 04 / 16$ & Fri 15/04/16 \\
\hline 16 & & Validxça BPP e Protótipo & 2 days & Mon 18/04/16 & Tue $19 / 04 / 16$ \\
\hline 17 & i & $\begin{array}{l}\text { Documentaçăo funcional WEB } \\
\text { (PUO4) }\end{array}$ & 7 days & Wed $20 / 04 / 16$ & Fri 29/04/16 \\
\hline 18 & 1 & $\begin{array}{l}\text { Especificaçlo funcional SAP } \\
\text { (PU04, PU02) }\end{array}$ & 2 days & Wed $20 / 04 / 16$ & Fri 22/04/16 \\
\hline 19 & & $\begin{array}{l}\text { Formalizar Encerramento da } \\
\text { Fase Planejamento }\end{array}$ & Odays & Fri 29/04/16 & Fri 29/04/16 \\
\hline 20 & & Fase 3 - Desenvolvimento & S4 days & Mon 25/04/16 & Fri 08/07/16 \\
\hline 21 & & SAP & 12 days & Mon 25/04/16 & Tue $10 / 05 / 16$ \\
\hline 22 & 1 & Desenvolviment SAP & 5 days & Mon 25/04/16 & Fri 29/04/16 \\
\hline 23 & 1 & Testes Unitźrios & 2 days & Mon 02/05/16 & Tue 03/05/16 \\
\hline 24 & 1 & Testes Integrados & 3 days & Wed $04 / 05 / 16$ & Fri $06 / 05 / 16$ \\
\hline 25 & i & Passagem de Conhecimento & 1 day & Mon 09/05/16 & Mon 09/05/16 \\
\hline 26 & & Implantaçపo em Produç̄o & 1 day & Tue $10 / 05 / 16$ & Tue $10 / 05 / 16$ \\
\hline 27 & & $\begin{array}{l}\text { Cadastro de Agendamento e } \\
\text { Contingencia }\end{array}$ & 34 days & $\begin{array}{l}\text { Mon } \\
02 / 05 / 16\end{array}$ & Fri $17 / 06 / 16$ \\
\hline 28 & i & $\begin{array}{l}\text { Desenvolver Processo de } \\
\text { Cadastramento de } \\
\text { Agendamento }\end{array}$ & 30 days & Mon $02 / 05 / 16$ & Mon $13 / 06 / 16$ \\
\hline 29 & 1 & Elaborar Plano de Testes & 1 day & Fin $20 / 05 / 16$ & Fri 20/05/16 \\
\hline 30 & & Testes Integrados / Alustes & 4 days & Tue $14 / 06 / 16$ & Fri 17/06/16 \\
\hline 31 & & Formalizar Entrega (Aceite) & Odays & Fn $27 / 06 / 16$ & Fri $17 / 06 / 16$ \\
\hline 32 & & Relatórios & 15 days & Mon 20/06/16 & Fri 08/07/16 \\
\hline 33 & 1 & $\begin{array}{l}\text { Desenvolver Relatórios de } \\
\text { Contingéncia }\end{array}$ & 10 days & Mon 20/06/16 & Fri 01/07/16 \\
\hline 34 & 1 & Elaborar Plano de Testes & 1 day & Tue $28 / 06 / 16$ & Tue $28 / 06 / 16$ \\
\hline
\end{tabular}

Quadro 9 - Cronograma implantação projeto de Agendamento via plataforma de internet

\section{3) RESULTADOS}

Quando falamos em gestão, principalmente nesse período turbulento, um dos problemas principais que vem à mente é como determinar se a empresa está indo bem e também, quais os aspectos poderiam ser melhorados ${ }^{6}$. Nesse sentido, os indicadores de desempenho são fundamentais por mensurar com medidas claras o desempenho da empresa de acordo com as necessidades de informação colocadas pela administração.

No quadro abaixo, demonstramos a evolução no tempo de permanecia dos veículos e seu reflexo na geração de estadias, deixando claro a eficácia do trabalho realizado.

\footnotetext{
6 BALLOU, Ronald H. Gerenciamento da cadeia de suprimentos: planejamento, organização e logística
} empresarial. $4^{a}$ ed. Porto Alegre: Bookmann, 2001 


\section{$35^{\circ}$ Logística}

\section{ISSN 1982-985X}

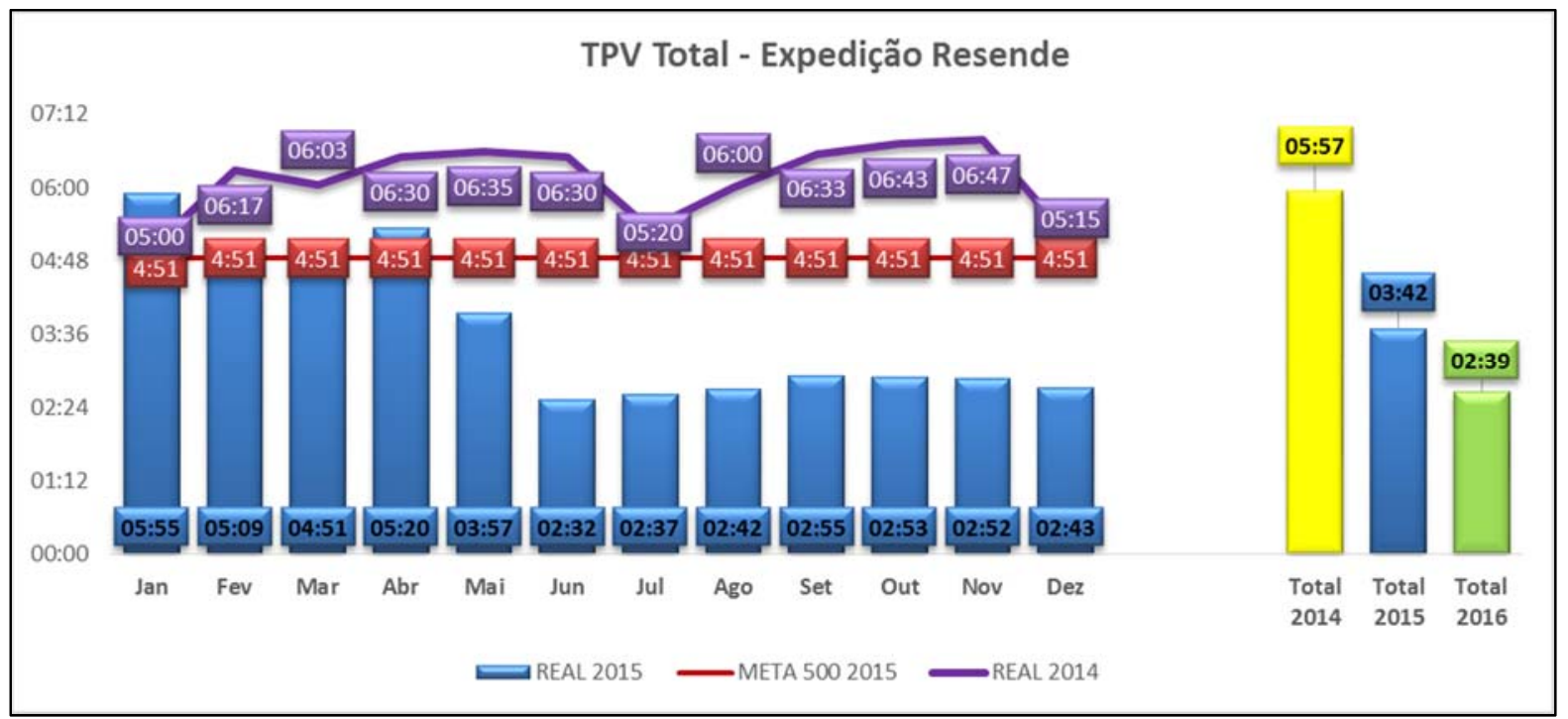

Quadro10 - Evolução do Tempo de permanência de Veículos (2014 a 2016, no processo de Expedição da unidade de Resende, Rio de Janeiro

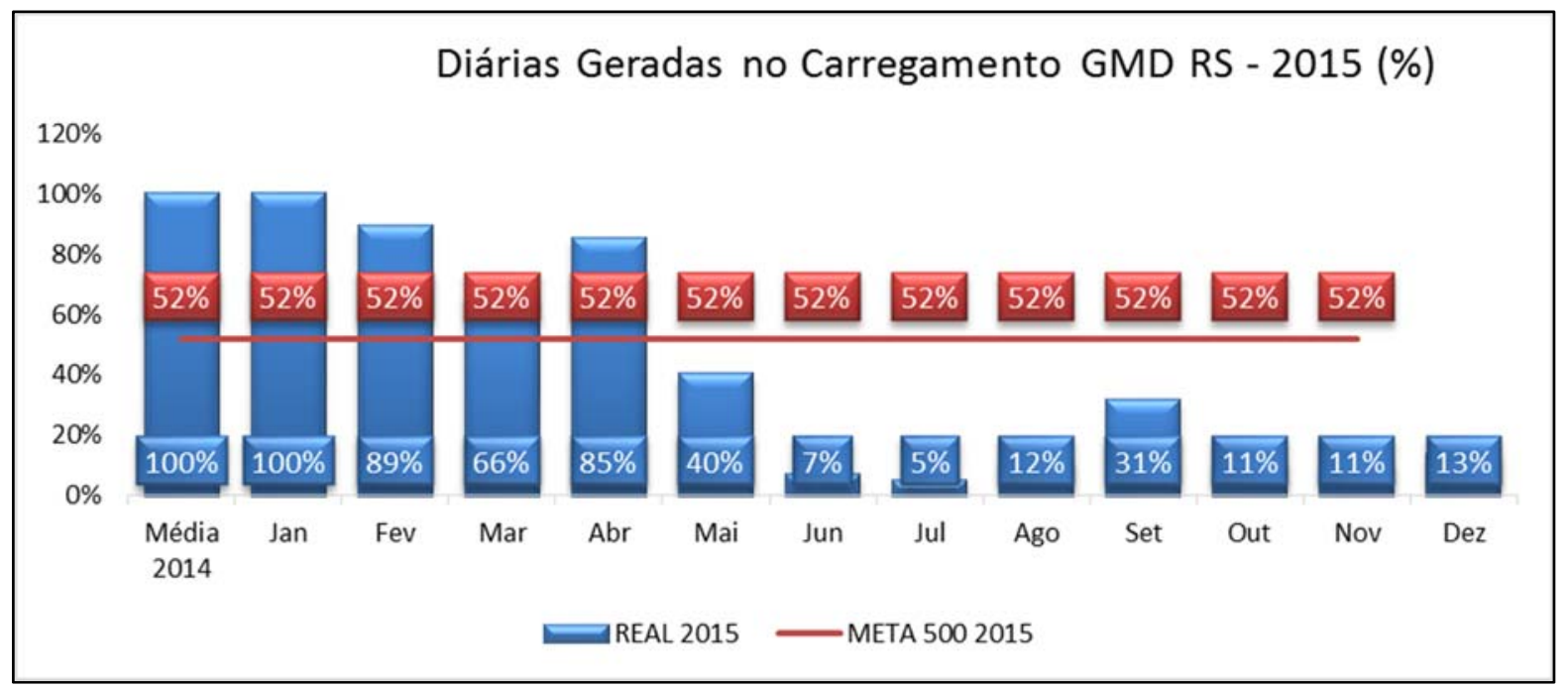

Quadro 11 - Evolução geração de estadias, em 2015, no processo de Expedição da unidade de Resende, Rio de Janeiro.

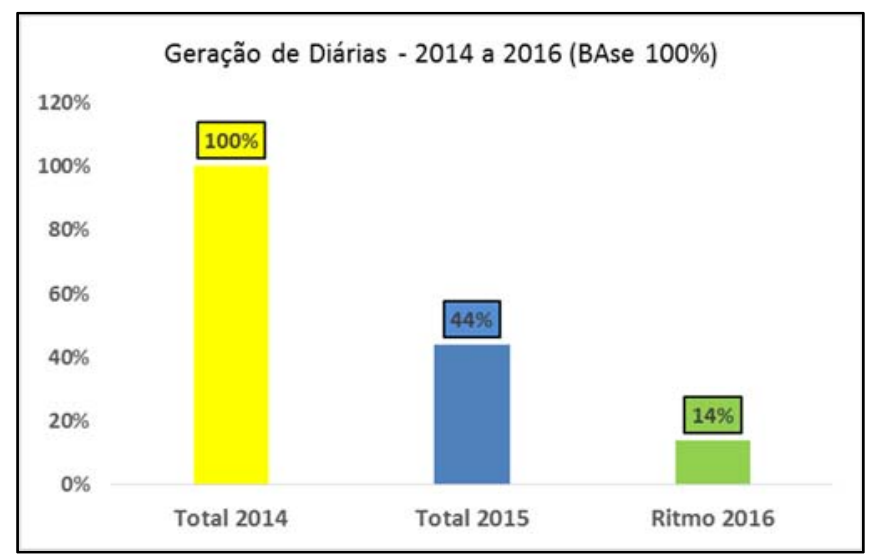

Quadro 12 - Evolução geração de estadias (2014 a 2016), no processo de Expedição da Unidade de Resende, Rio de Janeiro.

Com as medidas explicadas neste trabalho, a equipe de Supply Chain da Votorantim Siderurgia procura esclarecer que não há necessidade de grandes investimentos para grandes soluções. Precisamos sim, buscar cada vez mais, trabalhar de maneira inovadora e seguir sempre na busca pela excelência. 
Com essa solução, seguimos em busca de um de nossos objetivos, que é ser reconhecido como o embarcador mais confiável do Sul Fluminense, garantindo produtividade aos recursos de transportes que são ofertados por nossos provedores logísticos, gerando assim, maior atratividade e menor dificuldade na contratação de veículos e nas negociações comerciais relacionadas a conta frete.

\section{Agradecimentos}

O trabalho só foi possível graças ao envolvimento das equipes de Supply Chain das usinas de Barra Mansa e Resende da Votorantim Siderurgia e dos Transportadores que nos atendem nestas unidades. Equipes estas, aos quais dedicamos nossos agradecimentos e reconhecimento.

\section{REFERÊNCIAS}

1 DRUCKER, Peter - Administração e Marketing - Análise, Planejamento e Controle. Ed. Atlas, 1985;

2 BALLOU, Ronald H. Gerenciamento da cadeia de suprimentos: planejamento, organização e logística empresarial. $4^{a}$ ed. Porto Alegre: Bookmann, 2001;

3 BAPTISTA, LG - Apostila sobre estratégia das Empresas - FGV - 2008;

4 GAMEIRO A H, CAIXETA -FILHO J. V., Sistema de Gerenciamento de Transporte, São Paulo, Editora Atlas, 2001.

5 Sistema de Gestão Integrada da Votorantim Siderurgia - GOL. 